\title{
Accelerated and natural carbonation of concretes with internal curing and shrinkage/viscosity modifiers
}

\author{
A. Durán-Herrera · J. M. Mendoza-Rangel • \\ E. U. De-Los-Santos $\cdot$ F. Vázquez $\cdot$ P. Valdez \\ Dale P. Bentz
}

Received: 19 September 2013/Accepted: 26 November 2013

(C) RILEM 2014

\begin{abstract}
In many parts of the world, corrosion of reinforcing steel in concrete induced by carbonation of the concrete continues to be a major durability concern. This paper investigates the accelerated and natural carbonation resistance of a set of seven concretes, specifically evaluating the effects of internal curing and/or shrinkage/viscosity modifiers on carbonation resistance. In addition to five different ordinary portland cement (OPC) concretes, two concretes containing $20 \%$ of a Class F fly ash as replacement for cement on a mass basis are also evaluated. For all seven concrete mixtures, a good correlation between accelerated (lab) and natural (field) measured carbonation coefficients is observed. Conversely, there is less correlation observed between
\end{abstract}

A. Durán-Herrera · J. M. Mendoza-Rangel .

E. U. De-Los-Santos · F. Vázquez · P. Valdez

Universidad Autónoma de Nuevo León (UANL), Facultad de Ingeniería Civil, 66450 San Nicolás de los Garza,

NL, Mexico

\section{A. Durán-Herrera $(\square) \cdot$ P. Valdez}

Universidad Autónoma de Nuevo León (UANL), Centro de Innovación, Investigación y Desarrollo en Ingeniería y Tecnología (CIIDIT), 66450 San Nicolás de los Garza, NL, Mexico

e-mail: alejandro.duranhr@uanl.edu.mx

\section{P. Bentz}

Materials and Structural Systems Division, National Institute of Standards and Technology, 100 Bureau Drive, Stop 8615, Gaithersburg, MD 20899, USA the specimens' carbonation resistance and their respective 28 days compressive strengths, with the mixtures containing the shrinkage/viscosity modifier specifically exhibiting an anomalous behavior of higher carbonation resistance at lower strength levels. For both the accelerated and natural exposures, the lowest carbonation coefficients are obtained for two mixtures, one containing the shrinkage/viscosity modifier added in the mixing water and the other containing a solution of the same admixture used to pre-wet fine lightweight aggregate. Additionally, the fly ash mixtures exhibited a significantly higher carbonation coefficient in both exposures than their corresponding OPC concretes.

Keywords Accelerated testing - Carbonation · Fly ash · Internal curing · Natural exposure . Viscosity modifier

\section{Introduction}

While the carbon $\left(\mathrm{CO}_{2}\right)$ footprint of concrete has become a major concern in 21 st century sustainability discussions, the reaction of atmospheric carbon dioxide with concrete has been a durability concern for field-exposed reinforced concretes since the previous century [1]. As atmospheric carbon dioxide penetrates into and reacts with concrete (mainly with its calcium hydroxide component to produce calcium carbonate), this carbonation reduces the alkalinity $(\mathrm{pH})$ of the 
surrounding pore solution and can thus induce corrosion of the reinforcing steel by dissolving its passive surface layer. Greater $\mathrm{pH}$ reductions due to carbonation have been reported in concretes with supplementary cementitious materials $[2,3]$. The general consensus is that once the $\mathrm{pH}$ of the surrounding pore solution falls below nine, depassivation of the steel is imminent [4].

In the past few years, various paradigms for improving the performance of concrete have been introduced. The present study will focus on two such strategies, namely internal curing (IC) and shrinkage/ viscosity modifiers, and their influence on carbonation rates in both accelerated and natural exposures. In IC, small water reservoirs, typically consisting of prewetted fine lightweight aggregates (LWA), are incorporated into a concrete mixture to provide necessary additional curing water to mitigate chemical/autogenous shrinkage of the cement paste and to enhance hydration and the development of mechanical and transport properties [5]. Amongst other benefits, the improved hydration and a denser interfacial transition zone between LWA and paste could potentially contribute to a reduction in carbonation rates. This new curing paradigm has successfully moved from the laboratory to field practice [5], with bridge decks incorporating IC in their concrete mixtures being employed in the US states of Indiana, New York, and Utah, to name just a few. Conversely, the second strategy investigated in this paper, intentionally increasing the viscosity of the pore solution in the concrete, has only been evaluated in laboratory specimens to date [6]. While numerous chemicals can be employed to increase solution viscosity, those with molar masses below about $1,000 \mathrm{~g} / \mathrm{mol}$ have been shown to be the most efficient in cement-based materials [7]. In addition to approximately doubling the viscosity of pore solution, the viscosity modifier used in the present study also significantly reduces its surface tension, being conventionally employed as a shrinkage-reducing admixture (SRA).In laboratory studies, both IC and the viscosity modifier have been shown to decrease chloride diffusion rates [8] and to significantly reduce expansion measured during standard sulfate attack testing exposures [9]. Thus, it was of interest to investigate their effect on another primary concrete degradation process, carbonation. A secondary interest of the present study was to investigate any relationships between the performances of concretes exposed to either accelerated or natural carbonation environments [10].

\section{Materials and experimental procedures}

Seven different concretes were prepared using an ordinary portland cement (OPC) class CPO 40 that meets the Mexican standard NMX C144. Its reported chemical composition (obtained via X-ray fluorescence analysis) is provided in Table 1 . Its density and median particle diameter are $3,140 \mathrm{~kg} / \mathrm{m}^{3}$ and $20 \mu \mathrm{m}$, respectively. For the two concrete mixtures with fly ash, a coarse Class F fly ash with a low $\mathrm{CaO}$ content (Table 1) was employed to replace $20 \%$ of the cement by mass. Its density and median particle diameter are $2,640 \mathrm{~kg} / \mathrm{m}^{3}$ and $80 \mu \mathrm{m}$, respectively. Normal weight limestones with maximum sizes of 19 and $5 \mathrm{~mm}$, respectively, were employed as coarse and fine aggregate. For mixtures with internal curing (either water or a water-admixture solution in the fine lightweight aggregate), a portion of the normal weight sand was replaced with fine lightweight aggregate (LWA), a locally available pumice. Figure 1 presents the grain size distributions of the limestone and pumice sands with fineness moduli of 3.1 and 2.5, respectively. Other relevant characteristics of these three aggregates are summarized in Table 2 .

A polycarboxylate-based high range water reducer with a water content of $79 \%$ was used in all of the concrete mixtures. A commercially available shrinkage-reducing admixture with a water content of $28 \%$ that both modifies (increases) viscosity and reduces surface tension (shrinkage-reducing) was used in four of the concrete mixtures. According to its product literature, this admixture provides secondary benefits (beyond shrinkage and cracking reduction) of reductions in compressive creep, curling, and carbonation. All concretes were prepared at a constant water-tocementitious materials ratio by mass $(w / \mathrm{cm}=0.40)$. For all the mixtures, the air content, determined according to ASTM C173 [11], was within a range of 2.3-2.8\%. Complete mixture proportions for all seven concrete mixtures are provided in Table 3.

A brief description of the seven concrete mixtures is as follows. The control concrete contained only cement, coarse aggregate, sand, water, and HRWRA. In the concrete with internal curing (IC), $20 \%$ by volume of the sand was replaced with prewetted 
Table 1 Chemical compositions (mass basis) of cement and fly ash

\begin{tabular}{lll}
\hline Oxide & $\begin{array}{l}\text { Content in } \\
\text { cement }(\%)\end{array}$ & $\begin{array}{l}\text { Content in fly } \\
\text { ash }(\%)\end{array}$ \\
\hline $\mathrm{CaO}$ & 65.49 & 2.29 \\
$\mathrm{SiO}_{2}$ & 20.71 & 63.78 \\
$\mathrm{Fe}_{2} \mathrm{O}_{3}$ & 2.35 & 4.99 \\
$\mathrm{Al}_{2} \mathrm{O}_{3}$ & 5.84 & 25.01 \\
$\mathrm{Na}_{2} \mathrm{O}$ & 0.37 & 0.64 \\
$\mathrm{~K}_{2} \mathrm{O}$ & 0.01 & 0.01 \\
$\mathrm{MgO}$ & 1.68 & 0.01 \\
$\mathrm{SO}_{3}$ & 1.99 & Not measurable \\
$\mathrm{P}_{2} \mathrm{O}_{5}$ & 0.12 & 0.02 \\
$\mathrm{TiO}_{2}$ & 0.22 & 0.93 \\
\hline
\end{tabular}

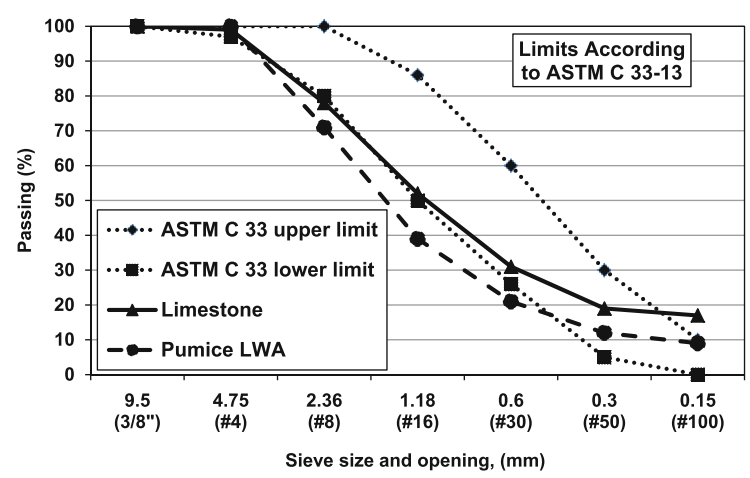

Fig. 1 Particle size distributions of limestone and pumice LWA sands in comparison to the limits found in ASTM C 33 [14]

lightweight pumice, where the pumice was prewetted with only water. The concrete designated as SRA contains a $1.5 \%$ dosage (per mass of cement) of shrinkage-reducing admixture (viscosity modifier) to the mixing water. This is equivalent to a $3.7 \%$ solution of the admixture being used in place of the mixing water employed in the control concrete. The mixture designated as IC+SRA combines the approaches employed in the previous two concretes with $20 \%$ replacement of pumice for sand and the $1.5 \%$ dosage of the SRA per unit mass of cement. The mixture designated as VERDiCT also combines the viscosity modifier and IC approaches, but as opposed to the previous mixture in which the two technologies are introduced separately, here the LWA are prewetted with a 50:50 solution of the SRA in water, while
Table 2 Aggregate characteristics

\begin{tabular}{llll}
\hline Aggregate & $\begin{array}{l}\text { Bulk } \\
\text { density } \\
\left(\mathrm{kg} / \mathrm{m}^{3}\right)\end{array}$ & $\begin{array}{l}\text { Density }\left(\mathrm{kg} / \mathrm{m}^{3}\right) \\
(\text { specific gravity) }\end{array}$ & $\begin{array}{l}\text { Absorption } \\
(\%)\end{array}$ \\
\hline Coarse limestone & 1,543 & 2,660 & 0.63 \\
Sand limestone & 1,597 & 2,630 & 2.25 \\
Pumice LWA & 849.4 & 1,570 & 33.00 \\
\hline
\end{tabular}

maintaining a $20 \%$ volumetric replacement of sand by pumice. In this case, the SRA concentration would correspond to a $9.3 \%$ solution (considering the total of the mixing water and the water added via the LWA). The final two concrete mixtures, designated as FA and FA-VERDiCT, are equivalent to the control and VERDiCT concretes but with $20 \%$ of the cement (by mass) replaced with the Class F fly ash.

Prior to concrete production, for internally cured mixtures, the pumice sand was saturated for $24 \mathrm{~h}$ under sealed conditions in a plastic bucket. According to the mixture proportions, the necessary dry mass of pumice followed by the corresponding mass of water or water-SRA admixture solution required to attain the pre-wetted condition were introduced to the bucket. For the $117 \mathrm{~kg}$ of SSD pumice LWA used to introduce internal curing (Table 3), $29 \mathrm{~kg} / \mathrm{m}^{3}$ of internal curing solution was used in mixtures IC and SRA. To mix the concrete, a $100 \mathrm{~L}$ capacity conventional drum mixer was employed. The mixing procedure was as follows: first, the interior of the drum was pre-wetted and after the normal weight coarse and fine aggregates, with approximately a mass of water equivalent to their absorption water, were introduced. Next, mixing was conducted for $30 \mathrm{~s}$ to homogenize the materials. Then, with the mixer turned off, the cementitious materials were introduced. After the initial homogenization of $30 \mathrm{~s}$, the whole mixing process consisted of $3 \mathrm{~min}$ of initial mixing, 3 min of rest and 3 min of final mixing. For mixtures implemented with internal curing or VERDiCT technologies, admixtures and LWA in prewetted conditions were introduced 60 and $20 \mathrm{~s}$ before initiating the final mixing period, respectively.

At the end of the mixing process, cylindrical specimens with $100 \mathrm{~mm}$ in diameter by $200 \mathrm{~mm}$ in height were molded for compressive strength determinations, and cylindrical specimens of $75 \mathrm{~mm}$ in diameter by $150 \mathrm{~mm}$ in height were cast for carbonation exposure and monitoring. For both determinations, specimens were produced in triplicate. All of the 
Table 3 Mixture proportions in $\mathrm{kg} / \mathrm{m}^{3}$ (aggregates in saturated-surface-dry [SSD] condition)

\begin{tabular}{|c|c|c|c|c|c|c|c|}
\hline & Control & $\mathrm{IC}$ & SRA & $\mathrm{IC}+\mathrm{SRA}$ & VERDiCT & FA & FA-VERDiCT \\
\hline Cement & 422 & 421 & 420 & 424 & 423 & 336 & 338 \\
\hline Fly ash & - & - & - & - & - & 84 & 85 \\
\hline Water & 168 & 168 & 165 & 166 & 168 & 167 & 168 \\
\hline Coarse aggregate & 789 & 788 & 785 & 788 & 791 & 781 & 786 \\
\hline Sand & 980 & 800 & 991 & 783 & 786 & 986 & 781 \\
\hline LWA & - & 117 & - & 117 & 117 & - & 117 \\
\hline SRA & - & - & 6.29 & 6.36 & 19.5 & & 19.3 \\
\hline HRWRA & 1.13 & 1.13 & 1.13 & 1.13 & 1.13 & 1.13 & 1.13 \\
\hline$w / \mathrm{cm}$ & 0.40 & 0.40 & 0.40 & 0.40 & 0.40 & 0.40 & 0.40 \\
\hline
\end{tabular}

specimens were demolded $24 \mathrm{~h}$ after casting, then placed in a standard curing room with controlled conditions of temperature $\left(23 \pm 1.7^{\circ} \mathrm{C}\right)$ and relative humidity ( $\mathrm{RH} \geq 95 \%$ ), where they remained for 13 days. After this 14 days period, specimens remained under laboratory conditions until their time of testing or being exposed to their carbonation environment. Specimens for natural carbonation were placed on a metallic rack in an industrial environment at a local chemical plant, with environmental conditions as reported in Table 4. Specimens for accelerated carbonation were placed in a laboratory carbonation chamber with the controlled exposure conditions shown in Table 4 , where the \pm values indicate the normal operating range of the equipment encountered when running the experiment.

Compressive strengths were measured at 14, 28, 90, and 180 days; results are presented in Table 5. Both the accelerated and natural carbonation exposures were initiated after 28 days of curing. For both exposures, carbonation depths were contrasted using a phenolphthalein solution sprayed over the greensplit surfaces of the specimens. Carbonation depths for accelerated and natural exposures are reported in Tables 6 and 7 (respectively) and Fig. 2. Average depths indicated in Fig. 2 are the mean value of eight measurements per specimen.

\section{Results and discussion}

Mixtures IC, SRA, IC+SRA, and VERDiCT all presented lower compressive strengths than the control mixture; diminutions were higher at 14 and 28 days with maximum values of $18,14,18$ and
Table 4 Exposure conditions for accelerated and natural exposure to carbonation

\begin{tabular}{lcl}
\hline Parameter & \multicolumn{2}{l}{ Carbonation exposure } \\
\cline { 2 - 3 } & Accelerated & Natural \\
\hline Temperature & $30 \pm 2{ }^{\circ} \mathrm{C}$ & $27-45^{\circ} \mathrm{C}$ \\
$\mathrm{RH}$ & $65 \pm 5 \%$ & $18-60 \%$ \\
$\mathrm{CO}_{2}$ level & $40,000 \pm 1,000 \mathrm{mg} / \mathrm{kg}$ & $200-900 \mathrm{mg} / \mathrm{kg}$ \\
\hline
\end{tabular}

$20 \%$, respectively. At later ages (90 and 180 days) the maximum reduction values were $6,8,12$, and $12 \%$, respectively.

Strength diminutions are attributed to both the porous nature of the LWA and a retarding influence of the shrinkage-reducing admixture [8]. Subsequent strength improvements at later ages are attributed to a further hydration and higher matrix densification due to internal curing. Similar behavior is observed when the FA-VERDiCT mixture is compared with the FA mixture, with maximum diminutions of $11 \%$ between 14 and 28 days, reduced to $8 \%$ between 90 and 180 days.

Carbonation depth versus time is typically analyzed as a diffusion phenomenon and fitted to an equation first proposed by Tuutti [12]:

$x=K \sqrt{t}$

where $x$ is the average carbonation depth (mm), $K$ is the carbonation coefficient (mm/year $\left.{ }^{0.5}\right)$, and $t$ is the exposure time to $\mathrm{CO}_{2}$ (year). To verify that this equation properly describes the data obtained in this study, Fig. 2 provides a plot of the measured carbonation depths versus the square root of time for the two exposure conditions, accelerated and natural, for each 
Table 5 Measured average compressive strengths and standard deviations for the seven concrete mixtures

\begin{tabular}{lllll}
\hline Mixture & Strength (14 days) $\mathrm{MPa}$ & Strength (28 days) $\mathrm{MPa}$ & Strength (90 days) $\mathrm{MPa}$ & Strength (180 days) MPa \\
\hline Control & $42.4 \pm 3.7$ & $53.1 \pm 1.7$ & $52.6 \pm 3.9$ & $53.9 \pm 2.7$ \\
IC & $34.8 \pm 0.9$ & $49.1 \pm 1.4$ & $49.7 \pm 0.8$ & $50.6 \pm 0.5$ \\
SRA & $36.5 \pm 5.3$ & $46.0 \pm 3.0$ & $48.3 \pm 2.6$ & $50.1 \pm 1.4$ \\
IC+SRA & $38.4 \pm 1.2$ & $43.8 \pm 0.8$ & $47.5 \pm 0.3$ & $47.6 \pm 1.1$ \\
VERDiCT & $37.8 \pm 1.0$ & $42.6 \pm 0.3$ & $46.8 \pm 1.5$ & $47.3 \pm 2.8$ \\
FA & $33.7 \pm 1.9$ & $39.2 \pm 2.8$ & $46.8 \pm 0.4$ & $47.7 \pm 1.7$ \\
FA-VERDiCT & $31.0 \pm 1.3$ & $34.8 \pm 3.5$ & $43.0 \pm 2.0$ & $43.5 \pm 1.7$ \\
\hline
\end{tabular}

Table 6 Average, minimum and maximum carbonation depths ( $\mathrm{mm}$ ) for accelerated exposure

\begin{tabular}{llllr}
\hline Mixture & \multicolumn{4}{l}{ Exposure time as sqrt (time) (year ${ }^{0.5}$ ) (days) } \\
\cline { 2 - 5 } & $\begin{array}{l}\text { 0.196 }(14 \text { days) } \\
\text { Average (min-max) }\end{array}$ & $\begin{array}{l}0.277 \text { (28 days) } \\
\text { Average (min-max) }\end{array}$ & $\begin{array}{l}\text { 0.497 (90 days) } \\
\text { Average (min-max) }\end{array}$ & $\begin{array}{l}0.641(150 \text { days) } \\
\text { Average (min-max) }\end{array}$ \\
\hline Control & $2.20(0.97-3.25)$ & $4.00(1.83-7.72)$ & $8.91(6.01-12.97)$ & $11.05(3.14-21.14)$ \\
IC & $3.10(1.21-4.90)$ & $4.39(1.71-8.23)$ & $8.68(5.07-11.92)$ & $9.61(3.18-14.22)$ \\
SRA & $2.58(0.00-9.53)$ & $3.39(1.57-7.70)$ & $7.58(4.64-9.96)$ & $8.92(3.64-15.47)$ \\
IC-SRA & $2.89(1.10-6.80)$ & $3.97(1.68-6.47)$ & $7.71(5.67-11.88)$ & $8.05(4.24-12.55)$ \\
VERDiCT & $2.42(0.80-3.84)$ & $3.38(1.86-6.99)$ & $7.49(5.55-10.02)$ & $9.47(4.53-13.9)$ \\
FA & $2.63(1.64-4.16)$ & $4.18(2.25-5.62)$ & $10.76(8.73-14.44)$ & $10.26(4.53-14.41)$ \\
FA-VERDiCT & $3.26(2.04-4.71)$ & $5.13(2.93-7.00)$ & $10.84(6.77-13.97)$ & $10.97(2.28-17.32)$ \\
\hline
\end{tabular}

Table 7 Average, minimum and maximum carbonation depths (mm) for natural exposure

\begin{tabular}{lllll}
\hline Mixture & \multicolumn{4}{l}{ Exposure time as sqrt (time) $\left(\right.$ year $\left.^{0.5}\right)$ (days) } \\
\cline { 2 - 5 } & $\begin{array}{l}0.196(14 \text { days) } \\
\text { Average (min-max) }\end{array}$ & $\begin{array}{l}0.277 \text { (28 days) } \\
\text { Average (min-max) }\end{array}$ & $\begin{array}{l}0.497 \text { (90 days) } \\
\text { Average (min-max) }\end{array}$ & $\begin{array}{l}0.641(150 \text { days) } \\
\text { Average (min-max) }\end{array}$ \\
\hline Control & $0.51(0.00-2.93)$ & $2.49(1.34-4.56)$ & $3.6(1.66-6.13)$ & $3.75(1.97-6.29)$ \\
IC & $1.78(0.00-4.67)$ & $3.24(1.64-5.72)$ & $4.31(2.34-7.15)$ & $4.43(2.50-6.54)$ \\
SRA & $0.63(0.00-3.42)$ & $2.48(1.65-4.29)$ & $3.16(1.43-5.61)$ & $3.38(1.63-5.15)$ \\
IC-SRA & $0.78(0.00-2.31)$ & $3.11(0.87-5.47)$ & $3.74(2.12-6.21)$ & $3.74(1.48-5.25)$ \\
VERDiCT & $0.78(0.00-3.14)$ & $2.59(0.57-5.44)$ & $3.28(2.22-4.90)$ & $3.91(1.93-6.13)$ \\
FA & $1.74(0.00-3.49)$ & $3.21(1.92-4.73)$ & $4.87(3.02-7.31)$ & $5.52(2.99-7.33)$ \\
FA-VERDiCT & $2.04(0.84-4.76)$ & $2.95(1.46-5.44)$ & $4.44(1.79-7.18)$ & $4.92(1.80-8.62)$ \\
\hline
\end{tabular}

of the seven concrete mixtures. A generally linear relationship, with some scatter, is observed. The correlation coefficients $\left(R^{2}\right)$ for the various carbonation data sets obtained when regressing carbonation depth versus the square root of time (Eq. 1) were all higher than 0.94 , with the majority being higher than 0.98 . The obtained carbonation coefficients are provided in Table 8 . With the coefficients obtained for the natural exposure conditions, the estimated times required for the carbonation fronts to reach a depth of $25 \mathrm{~mm}$ within the concretes, are presented in Table 9.

For the accelerated-controlled laboratory conditions, carbonation coefficients calculated according to the Tuuti model (Eq. 1) were between 2 and 2.5 times the carbonation coefficients of the natural carbonation exposure conditions as shown in Fig. 3. Results in Table 9 indicate that SRA delayed the time required 

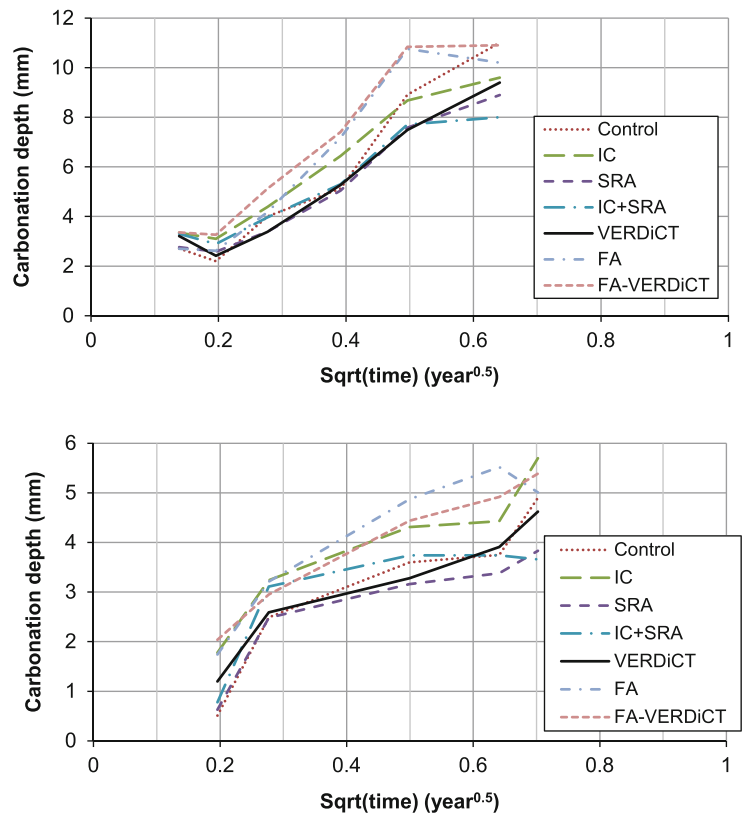

Fig. 2 Average carbonation depths versus square root of exposure time for accelerated (top) and natural (bottom) exposures. Range of measured values is provided in Tables 6 and 7

Table 8 Carbonation coefficients $(\mathrm{K})$ for accelerated and natural exposures for the concretes, along with standard error in coefficients

\begin{tabular}{lll}
\hline $\begin{array}{l}\text { Concrete } \\
\text { mixture }\end{array}$ & $\begin{array}{l}\text { Accelerated }\left(\mathrm{mm} / \text { year }^{0.5}\right) \\
\text { (standard error) }\end{array}$ & $\begin{array}{l}\text { Natural }\left(\mathrm{mm} / \text { year }^{0.5}\right. \\
\text { (standard error) }\end{array}$ \\
\hline Control & $16.3(0.9)$ & $6.65(0.53)$ \\
IC & $16.2(0.7)$ & $8.07(0.58)$ \\
SRA & $14.0(0.6)$ & $5.71(0.50)$ \\
IC+SRA & $13.9(0.9)$ & $6.19(0.78)$ \\
VERDiCT & $14.5(0.7)$ & $6.58(0.37)$ \\
FA & $17.7(1.2)$ & $8.45(0.64)$ \\
FA-VERDiCT & $18.8(1.0)$ & $8.18(0.45)$ \\
\hline
\end{tabular}

by the carbonation front to reach a depth of $25 \mathrm{~mm}$ by $35 \%$ when used in solution with the mixing water (mixture SRA) and by $16 \%$ when used in the same way together with water internal curing (mixture IC+SRA). VERDiCT and IC mixtures, required similar and less time respectively to advance to such a depth, in comparison to the control mixture.

Compared to the control mixture, conventional internal water curing (mixture IC) accelerates the advancement of the front of carbonation by about $20 \%$, as the porous fine LWA apparently may provide
Table 9 Estimated time required by the front of carbonation to reach a depth of $25 \mathrm{~mm}$ in the natural exposure environment

\begin{tabular}{lc}
\hline Concrete mixture & Time (years) \\
\hline Control & 14.1 \\
IC & 9.6 \\
SRA & 19.2 \\
IC+SRA & 16.3 \\
VERDiCT & 14.4 \\
FA & 8.8 \\
FA-VERDiCT & 9.3 \\
\hline
\end{tabular}

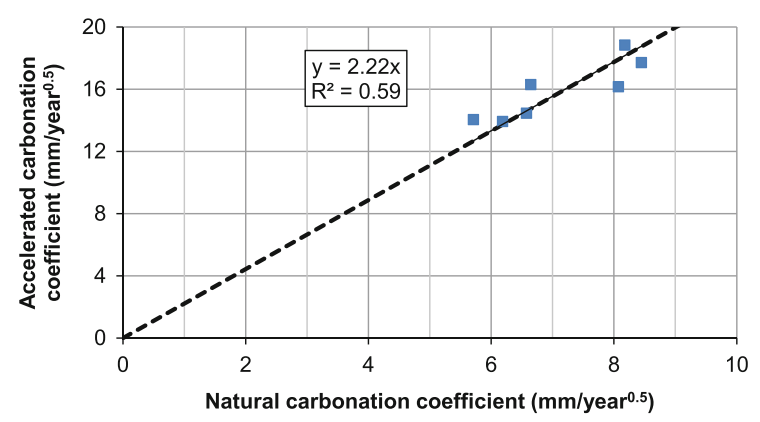

Fig. 3 Accelerated versus natural carbonation coefficients for the seven concrete mixtures. Standard errors for the plotted coefficients can be found in Table 8

additional pathways for the ingress of $\mathrm{CO}_{2}$. While several studies comparing the carbonation resistance of lightweight concrete and normal weight concrete can be found in the literature, that of Haque et al. [13] is perhaps most relevant to the current study. These authors found that after 7 days of initial curing, the carbonation depth measured for lightweight concrete was only slightly greater than that measured for normal weight concrete, at similar strength levels. However, in a third mixture where the lightweight sand was replaced with normal weight sand, while the lightweight coarse aggregate was maintained, the measured carbonation depth was drastically reduced. This result supports the hypothesis that the fine porous LWA do contribute to an increased carbonation depth.

In the present study, the VERDiCT mixture did not exhibit improved concrete carbonation resistance in OPC concrete and delayed the front of carbonation advancement by only about $6 \%$ when fly ash was incorporated into the mixtures. The VERDiCT results are consistent with the benefits of improved carbonation resistance due to the presence of the SRA being offset by the previously discussed negative impact of the porous 


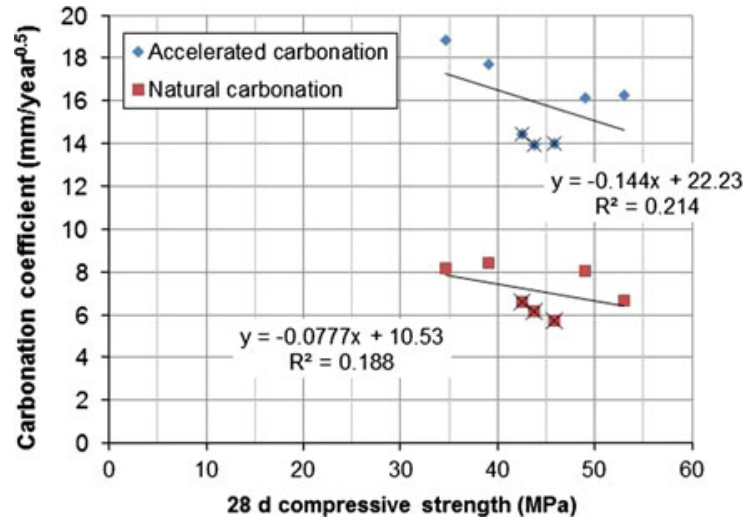

Fig. 4 Carbonation coefficients versus 28 days compressive strength for the seven concrete mixtures. Data points marked with an $X$ represent concrete mixtures containing the shrinkage/ viscosity modifier (but no fly ash). Standard errors for carbonation coefficients and standard deviations in measured compressive strengths can be found in Tables 5 and 8 , respectively

LWA. The highest carbonation coefficients for both exposures were exhibited by the two mixtures containing fly ash, as these mixtures may contain less calcium hydroxide to react with the ingressing $\mathrm{CO}_{2}$, leading to greater penetration depths of the carbonation front $[2,3]$.

Correlation coefficients $\left(R^{2}\right)$ for regressions between accelerated versus natural carbonation exhibit an intermediate correlation of 0.6. Neves et al. [10] have also observed a reasonable correlation between carbonation coefficients for natural and accelerated exposures, but with a significantly higher accelerated carbonation coefficient due to their exposure to a $5 \%$ $\mathrm{CO}_{2}$ environment. Conversely, as shown in Fig. 4, when plotting carbonation coefficients versus 28-days compressive strength, only a weak correlation of about 0.2 is observed. In the latter plot, particularly the mixtures with the SRA (without fly ash) are anomalous, exhibiting a higher carbonation resistance than would be indicated by their measured compressive strength.

\section{Conclusions}

Based on aforementioned results and commentaries, the following conclusions can be drawn:

1. For the accelerated carbonation exposure conditions, carbonation coefficients calculated according to the Tuuti model were between 2 and 2.5 times those obtained for the natural exposure conditions employed in this study. The performance rankings of the seven different concrete mixtures are nominally similar under the two different carbonation exposure conditions.

2. The concrete mixture with the shrinkage-reducing admixture administered directly in the concrete mixture presented the best performance in delaying the advancement of the carbonation front within the concrete.

3. Compared to the control OPC mixture, conventional internal curing with water (mixture IC) accelerated the advancement of the carbonation front by about $20 \%$ under natural exposure conditions during the 150 days time period evaluated in this study.

4. The VERDiCT technologie did not improve concrete carbonation resistance in OPC concrete and delayed the advancement of the carbonation front by only $6 \%$ when fly ash was incorporated into the mixtures.

5. The two mixtures with fly ash exhibited the highest carbonation coefficients for both natural and accelerated exposure conditions, likely due to their reduced calcium hydroxide contents.

Acknowledgments The authors would like to express their gratitude to the National Council of Science and Technology of Mexico (CONACYT) for the scholarships received by De-LosSantos and Vázquez for their MsC studies at UANL, to the Scientific and Technological Research Support Program of the UANL (PAICYT) and to CONACYT project number 155363 for the complementary economical support for this project. The authors also thank Charles K. Nmai from BASF Corporation, USA, and Daniel Canizales from BASF Mexico for providing the shrinkage-reducing admixture and the high range water reducer, respectively.

\section{References}

1. Parrott LJ (1987) A review of carbonation in reinforced concrete. Report 114, Cement and Concrete Association of Great Britain, Wexham Springs 43 pp

2. Sulapha P, Wong SF, Wee TH, Swaddiwudhipong S (2003) Carbonation of concrete containing mineral admixtures. J Mater Civ Eng 15(2):134-143

3. Valdez-Tamez PL, Durán-Herrera A, Fajardo-San Miguel G, Juárez-Alvarado C (2009) Influencia de la Carbonatación en Morteros Base Cementos Portland y Ceniza Volante. Ingenierías, Investigación y Tecnología; UNAM 10(1):3141

4. Pourbaix M (1974) Applications of electrochemistry in the corrosion science and in practice. Corros Sci 14:25-82 
5. Bentz DP, Weiss WJ (February, 2011) Internal curing: a 2010 state-of-the-art review. NISTIR 7765, US Department of Commerce

6. Bentz DP, Snyder KA, Peltz MA (2010) Doubling the service life of concrete structures. II: performance of nanoscale viscosity modifiers in mortars. Cement Concr Compos 32(3):187-193

7. Bentz DP, Snyder KA, Cass LC, Peltz MA (2008) Doubling the service life of concrete. I: reducing ion mobility using nanoscale viscosity modifiers. Cement Concr Compos 30(8):674-678

8. Bentz DP, Snyder KA, Peltz MA, Obla K, Kim H (2013) Viscosity modifiers to enhance concrete performance. ACI Mater J 110(5):495-502

9. Bentz DP, Davis JM, Peltz MA, Snyder KA (2013) Influence of internal curing and viscosity modifiers on resistance to sulfate attack. Mater Struct. doi 10.1617/s11527-0130081-X

10. Neves R, Branco F, de Brito J (2013) Field assessment of the relationship between natural and accelerated concrete carbonation resistance. Cement Concr Compos 41:9-15

11. ASTM International (2012) ASTM C173/C173 M-12 standard test method for air content of freshly mixed concrete by the volumetric method. West Conshohocken

12. Tuutti K (1982) Corrosion of steel in concrete. Swedish Cement and Concrete Research Institute, Stockholm

13. Haque MN, Al-Khaiat H, Kayali O (2004) Strength and durability of lightweight concrete. Cement Concr Compos 26:307-314

14. ASTM International (2013) ASTM C33/C33 M-13 standard specification for concrete aggregates. West Conshohocken 